Max-Planck-Institut für demografische Forschung

Max Planck Institute for Demographic Research

Konrad-Zuse-Strasse 1 · D-18057 Rostock · GERMANY

Tel +49 (0) 3812081 - 0; Fax +49 (0) 3812081 - 202;

http://www.demogr.mpg.de

MPIDR WORKING PAPER WP 2013-002

MARCH 2013

\title{
Interdisciplinary research collaboration as the future of ancient history? Insights from spying on demographers
}

Saskia Hin (hin@demogr.mpg.de)

This working paper has been approved for release by: Mikołaj Szołtysek (szoltysek@demogr.mpg.de), Deputy Head of the Laboratory of Historical Demography.

(C) Copyright is held by the authors.

Working papers of the Max Planck Institute for Demographic Research receive only limited review. Views or opinions expressed in working papers are attributable to the authors and do not necessarily reflect those of the Institute. 


\title{
'Interdisciplinary research collaboration as the future of ancient history? Insights from spying on demographers'
}

\author{
Saskia Hin*
}

\section{Introduction}

The conference program of 'Crossing Boundaries: ancient history explores its future' reveals that many of us see the future of ancient history as one in which interdisciplinary explorations take in a prominent place, and one in which 'interdisciplinary' is defined rather more broadly than it used to be: as encompassing findings and methods from disciplines as 'exotic' as climate research, genetics, medicine, economics, anthropology and biology. It is evident that the research directions we would like to see our own research, or our field, move into require intensive exchange of information between the humanities, the sciences and the social sciences. The facts suggest that we face quite a challenge in moving from where we are now: of a selected body of 1,110 publications written over the past decade by ancient historians who are currently employed at the top 10 Anglo-American Classics and Ancient History departments exactly four featured co-authors from unconventional departments: one economist, one biologist, one sociologist, and one involving a group of geneticists from a mixed range of departments. The share of 'crossing boundaries' collaborations in the wider, non-traditional definition - that is, interdisciplinary work involving ties beyond those with other humanities and classical archaeology departments - reaches just over $2 \%$ of all collaborative publications.

These are sobering statistics that illustrate the gap between our objectives and current outputs. They also lend vigour to what Robyn Veal in her abstract identifies as the challenge for ancient history: to take the initiative and encourage the flowering of collaborations across boundaries. My paper aims at encouraging debate on how we may actively foster such collaborations, and I will end my talk with some suggestions that result from daily opportunities to spy on how demographers structure and organize their research collaborations. Before doing so, however, I would like to draw attention to scholarly work on collaborative research; work that focuses on background factors associated and dissociated with research collaboration, investigates the relationship between research quality and research collaboration, and points to the role of research collaborations in fostering the generation of new ideas. Combining the findings of this literature with bibliometric investigation of publications in the field of ancient history and in the field of demography will help identify challenges for the future of interdisciplinary research in ancient history as well as strategies that may help overcome these challenges.

\section{Factors associated with research collaboration}

Recent years have witnessed a number of publications that investigate disincentives and incentives for research collaborations present in the academic research environment. Through regression analysis, these studies have revealed several covariates, or characteristics, that are associated with inclination or disinclination to be involved in joint, collaborative research. Among these are demographic as well as institutional factors: gender, tenure status and the type of institution a researcher is affiliated with all influence the likelihood that an individual researcher allocates research time to joint work.

A recent paper by Boardman and Corley illustrates that the direction of these associations is quite clear: as we see in Table 1, researchers affiliated with a research centre or institute were four times more likely to collaborate than those only affiliated with a university department. Institutional structure, in other words, matters, and the findings of this study fit in with a larger body of literature on research centres as tools to foster collaborative networks and create cross-disciplinary synergies. ${ }^{1}$ The explicit orientation towards interdisciplinarity of at least some of these institutes, and the physical proximity of scholars from different disciplines certainly play a role in creating this pattern.

\footnotetext{
*Max Planck Institute for Demographic Research, Konrad-Zuse-Strasse 1, 18057 Rostock, Germany. hin@demogr.mpg.de.

${ }^{1}$ Cf. e.g. Gibbons et al. (1994). See Boardman and Corley 2008 for further references.
} 
Table 1. Collaborative research by affiliation, tenure and gender: OLS regression results

Source: Boardman and Corley (2008). N=1,647

\begin{tabular}{lc} 
Individual characteristic of researcher & $\begin{array}{c}\text { Propensity towards } \\
\text { non-collaborative research }\end{array}$ \\
\hline Affiliated with research centre or research institute & $-4.13^{\star * *}$ \\
Tenured & -1.92 \\
Male & $6.8^{\star \star *}$ \\
& $* * *$ significant at $99 \%$
\end{tabular}

Second, those with tenure were twice more likely to co-author than those without tenure. It is likely that this association captures the effect of the number of years an individual has been working in a discipline: the more years of working experience, the more likely it becomes that a network has been built. ${ }^{2}$ But age and experience in the field may not be the only factor underlying the difference in collaborative propensity between tenured and untenured faculty. Several studies have found that another factor affecting willingness to cooperate is that of concerns about competition and fears about being "scooped". ${ }^{3}$ It has been demonstrated that such concerns affect propensities toward collaboration in virtually every respect: willingness to present and discuss work in progress with colleagues, to share data, to set up database systems and even to share resources with people with whom an individual already collaborates. ${ }^{4}$ The negative effect of the perceived or real pressure of scientific competition on collaboration propensity among individual researchers, one may hypothesize, is likely stronger for untenured than for tenured faculty.

Finally, Boardman and Corley's analysis revealed that gender was among the strongest predictors for collaboration: men were 6.8 times more likely than women to spend their research time working on solitary projects. The fact that many of the researchers covered by this study worked in an interdisciplinary setting seems to play an important role in producing this finding. When it comes to overall, general propensity to collaboration, studies find no consistent difference between men and women. But Boardman and Corley's finding tallies well with findings of other recent work specifically evaluating research with an interdisciplinary orientation. Empirical work by Rhoten and Pfirman on the UK and the US and by Van Rijnsoever and Hessels on The Netherlands found that female scientists are more inclined to step outside their disciplinary boundaries than their male counterparts, and they offer a number of hypotheses on the reasons that may underlie this behavioural distinction.

Research on the characteristics of researchers more involved in interdisciplinary collaboration versus those less involved thus provides us with first indications on what institutional and demographic factors are associated with propensities toward interdisciplinary collaboration in research. Evidently, the more environmental and individual level characteristics constitute obstacles toward achieving crossing boundaries research, the more researchers will need to be provided with personal incentives to engage in it, and the greater the need for platforms that facilitate productive interaction. This brings us to the issue of incentives for research collaboration.

\section{Incentives for research collaboration}

Why do others, in fields were collaboration is more common, collaborate? Figure 1 below depicts the topfour benefits of collaboration mentioned by a body of 195 university professors: increased knowledge, higher scientific quality of research output, the establishment of contacts and connections for future work and the generation of new ideas. Two of these, 'higher scientific quality' and 'generation of new ideas' require more detailed attention in this context.

\footnotetext{
${ }^{2}$ Van Rijnsoever and Hessels (2011); Lee and Bozeman (2005).

${ }^{3}$ Cf. e.g. Birnholz (2007).

${ }^{4}$ Birnholtz and Bietz (2003); Blumenthal et al. (1997) in which protecting one's scientific lead is provided as the number one reason for refusal to share data with other scientists by 2,167 faculty respondents; and Walsh and Hong 2003.

${ }^{5}$ Rhoten and Pfirman (2007); Van Rijnsoever and Hessels (2011).
} 
Fig. 1 Self-reported benefits of collaborative research

Note: Sources: Lee and Bozeman 2005; Melin 2000; N= 195 university professors

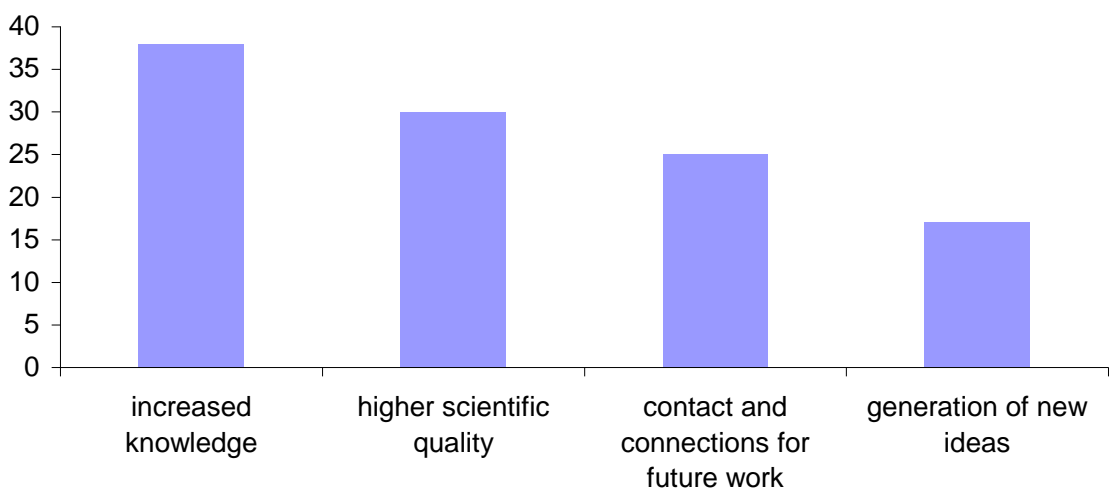

\subsection{Research quality}

Self-reported benefits, of course, unavoidably raise reliability issues: it cannot come as a surprise that researchers involved in collaborative research will attribute gains to their approach to scientific investigation. Does it really, and does it do so in the humanities, where this seems less evident? An Italian study by Franchescet and Costantini evaluated the data collected for the national Italian research assessment for 2001 to $2003 .{ }^{6}$ For this assessment, 18,500 publications were each submitted to two expert peer reviewers, who gave their judgement on the quality, importance, originality and internationalization levels of publications. Franchescet and Costantini compared their judgements on single authored papers versus multi-authored papers in many different fields, including some pertaining to the humanities. Their work suggests that the notion that research collaboration is beneficial from a purely scientific perspective is not merely an artefact of positive self-evaluation by scholars engaged in collaborative research. It tallies well with earlier research on the editorial judgements on paper submission, which found that significantly more papers by single authors were rejected for publication than was the case for multi-authored papers. ${ }^{7}$ Importantly, this effect is not limited to disciplines in which collaboration is the norm: in the humanities too jointly produced work was more often found to be of excellent quality by peer reviewers than work by performed by a single author (see Figure 2).

Fig. 2 Beyond perception: peer review reports on single and jointly authored publications Source: Franchescet and Costantini 2010

History, philosophy, psychology \& pedagogy

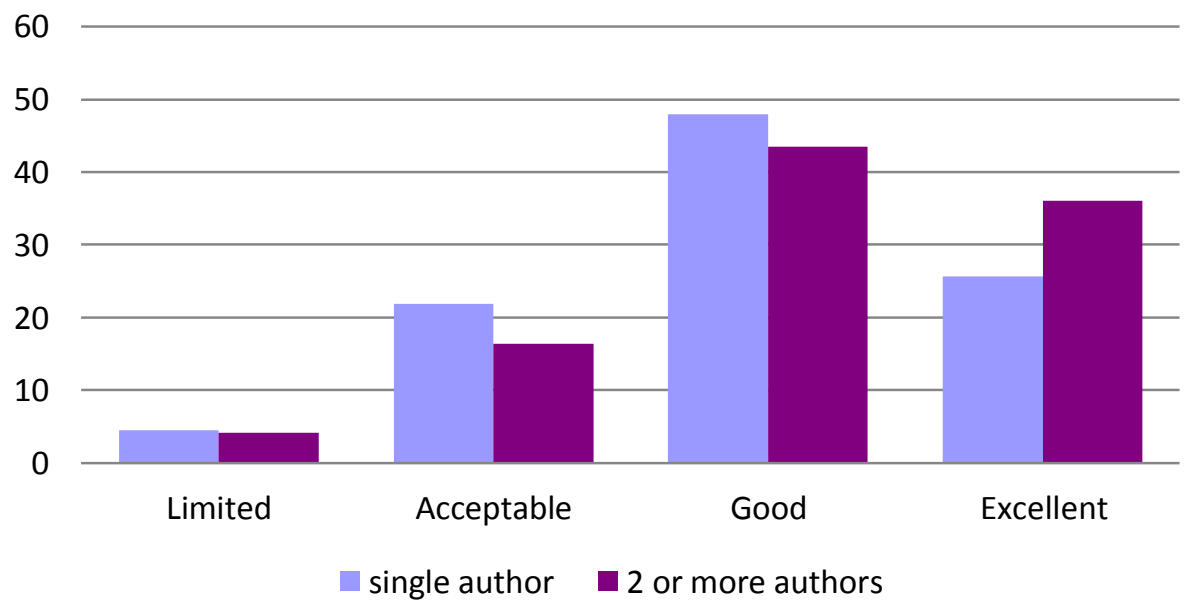

\footnotetext{
${ }^{6}$ Franchescet \& Costantini (2010).

${ }^{7}$ Presser (1980). The research was conducted on a social sciences journal; $66.9 \%$ of single author papers were rejected vs. $52.6 \%$ of co-authored papers.
} 


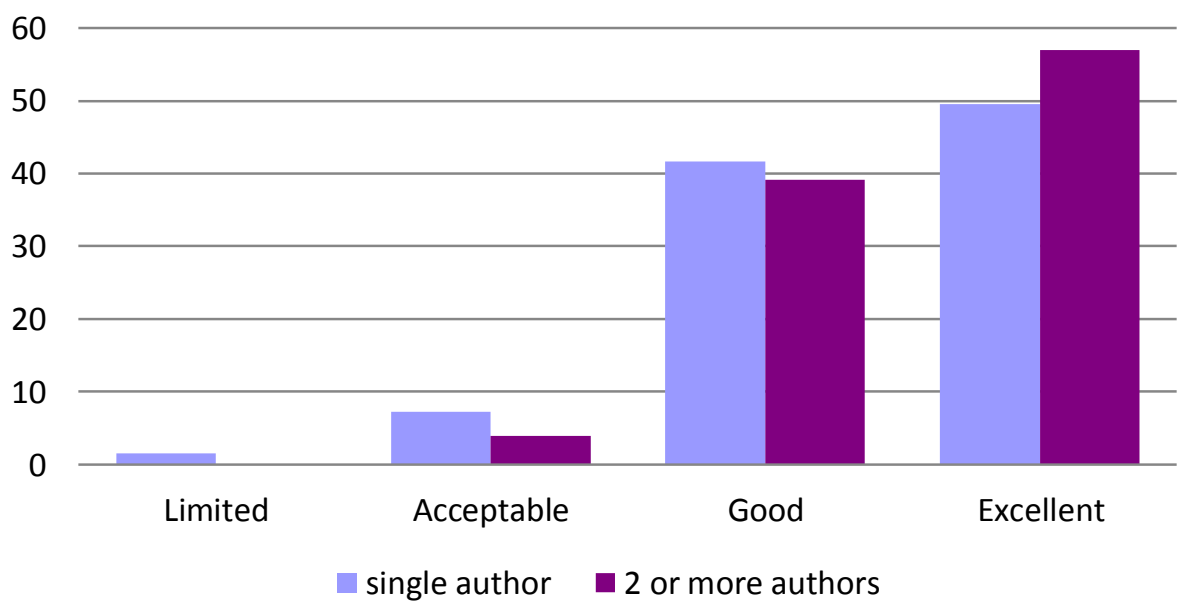

The benefits of joining forces are thus not limited to disciplines in which collaboration is required for access to the best equipment (including money), to the highest quality data or the most sophisticated methodological approaches. When it comes to fostering collaboration, raising awareness and understanding of the research quality benefits of (inter)disciplinary collaborations may therefore, as has been suggested, help by raising incentives at the individual level.

\subsection{Generation of new ideas}

The final top-four incentive for collaboration mentioned by university professors is that of the generation of new ideas. Some types of collaborations are more likely to spur new ideas and creative research advancement than others, namely collaborations that rank high on diversity. ${ }^{8}$ Bibliometric analysis of coauthorship has been used as one way to measure collaboration between scientists. ${ }^{9}$ I used this tool to gain a clearer idea of the demographic composition of research collaborations in ancient history, and to make a comparison with the research teams behind articles published in the journal Demography. Demography is one of the lead journals in the field of demography, which is dominated by joint research, strongly interdisciplinary and characterized by a strong presence of research institutes and population studies centres. In other words, this is a field that is relatively successful in fostering interdisciplinary collaborations. To what extent do research collaborations in ancient history and those in the field of demography share diversity characteristics, and on what fronts do they differ?

\section{Characteristics of research collaborations in ancient history}

\subsection{Data and methods}

In order to facilitate an empirical comparison of the demographics of research collaboration between two fields with highly divergent research cultures, that of ancient history and that of demography, I collected two samples of joint research publications, one for each field. Because joint research is the norm in one setting, but rather marginalized in the other, it was not feasible to collect both samples following the exact same criteria.

Table 2 gives an overview of the collected sample on ancient history publications, which consists in 174 jointly written publications ( $14.9 \%$ of a total of 1,110 publications reviewed). This sample covers publications written over the past decade by ancient historians currently employed at the ten leading Classics

\footnotetext{
${ }^{8}$ E.g. Barjak and Robinson (2008) on the positive effects of cultural diversity, as measured by international collaboration, on research outcomes.

${ }^{9}$ Cf. e.g. Logan and Shaw (1991). See also Melin (2000) for some critical notes on the limitations to this approach.
} 
and Ancient History departments in the UK and US. Publications were collected on the basis of online information. Faculty members as well as affiliated faculty whose first affiliation was with a history department ${ }^{10}$ were included in the sample population when their job title identified them as ancient historians, or, if titles were too unspecific or absent, on the basis of self-identification: that is, when they specified ancient history or a subfield of ancient history as (one of) their research interest(s). In order to obtain a sufficient number of joint publications, I reviewed publications covering the past decade (20022012) that were known from online CVs or departmental websites. It deserves emphasis that the 1,110 identifiable publications do not form a complete publication record of the individuals currently employed at the listed departments. In several cases, departmental websites only published 'representative' or 'top' publications. The consequences of this phenomenon are twofold: first, absolute numbers cannot be compared, and are not indicative of total research output. Second, the ultimate dataset of collaborative publications may miss out on some collaborative publications, perhaps more so than it misses out on publications in general (i.e. if individuals counted joint publications less frequently among their 'representative' or 'top' publications). On the other hand, I have used a rather (perhaps too) generous definition of collaborative research output, and included jointly edited works in the sample. This choice was based on the notion that contacts, connections, and interaction also form important dimensions of collaborative work ${ }^{11}$, and routes to foster interdisciplinarity and the generation of new ideas. These aspects of collaboration in research are furthered by jointly edited works even if this type of collaboration is less intensive than for jointly written papers or book chapters. The share of collaborative publications among the total publications should therefore, in sum, at best be taken as a rough indicator. There is no reason, however, to presume that the demographic composition of reported joint publications is a biased sample of the author teams behind the true number of jointly written publications.

\section{Table 2. Ten leading department in Classics \& Ancient History: known output and collaborative research}

\begin{tabular}{|c|c|c|c|c|}
\hline ID & University & $\begin{array}{l}\text { Faculty members } \\
\text { involved in } \\
\text { ancient history research }\end{array}$ & $\begin{array}{l}\text { Total listed } \\
\text { output } \\
(2002-2012)\end{array}$ & $\%$ Collaborative \\
\hline 1 & Cambridge (UK) & 13 & 159 & 11 \\
\hline 2 & Columbia (US) & 10 & 70 & 16 \\
\hline 3 & Durham (UK) & 8 & 113 & 21 \\
\hline 4 & Harvard (US) & 3 & 7 & (14) \\
\hline 5 & King's College London (UK) & 10 & 104 & 17 \\
\hline 6 & Oxford (UK) & 20 & 142 & 13 \\
\hline 7 & Pennsylvania (US) & 9 & 89 & 15 \\
\hline 8 & Princeton (US) & 10 & 108 & 16 \\
\hline 9 & Stanford (US) & 6 & 126 & 25 \\
\hline \multirow[t]{2}{*}{10} & University College London (UK) & 7 & 192 & 14 \\
\hline & Totals and average & 96 & 1,110 & $14.9 \%(\mathrm{~N}=174)$ \\
\hline
\end{tabular}

Note: dataset includes all known publications by faculty in Classics \& Ancient History departments, as well as affiliated staff whose primary affiliation was with a history department. Faculty members were classified as involved in ancient history research on the basis of job title and/or described interests. Publications were derived from department websites and uploaded CVs. Top-5 UK departments were selected following UK Research Assessment Exercise 2008; Top-5 US departments following US National Research Council 2010.

Identification of leading demographers was not possible following the same procedure: demographers are spread across a range of different departments, and top-listings of demography departments are not being published because there are too few universities with separate demography departments. Therefore, a different strategy was employed to identify leading demographers. In this case, I looked at publications in the

\footnotetext{
${ }^{10}$ Faculty members who had a secondary affiliation with a Classics \& Ancient History department but whose first affiliation was with a department other than History (e.g. literature studies, religious studies) were not included in the sample.

${ }^{11}$ Cf. Fig. 1 in which 'contacts and connections for future work' are included in the top-four of incentives for research collaboration, as well as the National Academy of Sciences (2004) report.
} 
lead journal Demography and focused on the authors of these papers. While the original aim was to then trace back the collaborative output of the first authors of these leading papers over the past decade, first investigations quickly showed that this would lead to a database too sizeable for the purposes of this paper. The comparative dataset has therefore been limited to the author teams of joint publications published in Demography 2012, which, while on the small side ( $\mathrm{N}$ of joint publications $=62$ ), proved large enough to identify trends and divergences in the composition of research collaborations between the two research fields.

For each of the co-authored publications, I collected information on the academic rank and affiliation of each of the co-authors at the time of publication. Furthermore, sex and age data were retrieved. When year of birth was unknown, which was the case for the majority of individuals in the sample, I used the year of award of BA, MA or $\mathrm{PhD}$ degree (always the degree for which information was available on all co-authors ${ }^{12}$ ) as a proxy to allow for an estimate of age differences between collaborators.

Evidently, the fact that the two datasets have not been collected following the exact same data collection procedure brings along some comparability issues. Notably, the ancient history publications relate to the past decade whereas the demography publications relate to the past year only. Since the past decades have witnessed trends of increasing collaboration across research disciplines ${ }^{13}$, the inclusion of older publications for ancient history may thus overstate the divergence in the share of joint publications between the fields of ancient history and that of demography. But as our interest here is in the composition of research collaborations rather than in the share of collaborative research, this problem does not undermine the results of the current undertaking. The dataset for demography solely includes articles published in a top-rank journal, whereas that for ancient history covers any type of co-authored publication. This may suggest stronger selection pressures in the former case, with, one might hypothesize, a stronger tendency for demography publications to have high status, and perhaps hence more homogeneous, author teams. As we shall in see the results section, however, this potential selection bias did not have a great bearing on the comparative results.

\subsection{Results}

Table 3 presents descriptive summary finds on diversity in research collaborations in ancient history. Note that sex, academic rank and affiliation where coded in order to allow for quantitative analysis. In each case, measures of diversity refer to the highest level of diversity measured between any two co-authors. So, for example, if three associate professors would have co-authored a paper with one assistant professor, the diversity score would be two, as I begin counting with 1 for same-rank co-authorships (cf. also the note to Table 3).

Table 3. The demography of joint research in ancient history: homogeneity or heterogeneity?

\begin{tabular}{|ccccc|} 
Diversity measure & N & $\begin{array}{c}\text { Mean difference } \\
\text { between co-authors }\end{array}$ & $\begin{array}{c}\text { Observed range } \\
\text { (min-max) }\end{array}$ & $\begin{array}{c}\text { Standard } \\
\text { deviation }\end{array}$ \\
Academic rank & 148 & 2.3 & $1-6$ & 1.5 \\
Geography & 155 & 2.9 & $1-4$ & 1.1 \\
Age difference & 12 & 17.6 & $4-26$ & 7.8 \\
Age difference proxied (degree) & 59 & 11.4 & $0-39$ & 11.4 \\
Gender & 166 & 1.5 & $1-2$ & 0.5 \\
\hline
\end{tabular}

Note: Academic rank diversity ranges from 1 to 6 . A score of 1 signifies that there was no rank difference between any of the co-authors; a score of 2 represents a collaboration with a maximum difference of one academic rank between any of the co-authors, and so on for scores 3 to 5 . A score of 6 represents collaborations between university faculty and nonfaculty, e.g. collaborators employed in business companies or non-academic staff. Geographic diversity ranges from 1 to 4 , in which 1 equals a collaboration between two members of the same department, 2 a collaboration between faculty of the same university, 3 a within-country collaboration, and 4 an international collaboration. Age differences and age difference proxies are in number of years. In the gender variable, a score of 1 represents a same-sex collaboration, whereas a score of two represents collaborations between men and women.

\footnotetext{
${ }^{12}$ If for none of these degrees, information was available on all co-authors, the variable 'age difference proxied (degree)' was coded as missing.

${ }^{13}$ Cf. e.g. Gazni et al. (2012) with further references.
} 
When we compare the obtained diversity scores to diversity scores for articles published in Demography, two results stand out: first, the marginalized role of collaborative research in ancient history does not coincide with lower scores on diversity in research collaboration overall. There does not seem to be, in other words, a clear relationship between the spread and acceptability of research collaborations and the level of heterogeneity of research collaborations. Remarkably, in fact, ancient history collaborations are more diverse on one of the measured dimensions: they score higher on what has been coined as 'the cosmopolitan scale'. Ancient historians, in other words, collaborate relatively frequently with scholars outside the own country of residence. Networks are slightly more international than those in demography. This pattern may well result from the availability of collaborative partners: as demographers seek collaborations with a wider range of disciplines than do ancient historians, chances that co-authors can be found at the same university or in the same country rise. Co-authored publications in demography slightly more frequently involve both men and women than do those in ancient history, but the observed difference here is not significant and may vary with sample size.

\section{Table 4. Diversity in research collaborations: a comparison between research in ancient history and demography}

$\begin{array}{ccc}\text { Diversity measure } & \text { Mean difference } & \text { between co-authors } \\ & \text { Ancient history } & \text { Demography } \\ \text { Academic rank } & 2.3^{* * *} & 3.3^{\star * *} \\ \text { Geography } & 2.9^{\star} & 2.8^{\star} \\ \text { Age difference } & 17.6 & \mathrm{NA} \\ \text { Age difference proxied (degree) } & 11.4^{* *} & 20.7^{* *} \\ \text { Gender } & 1.5 & 1.6\end{array}$

Note: $\mathrm{N}$ of publications in Demography: 53. $\mathrm{N}$ of ancient history publications: 174.

${ }^{* \star *}$ difference is significant at $99.99 \%$ level $(P=0.000)$ in Wilcoxon-Mann-Whitney test for differences between sample means; ${ }^{* *}$ difference is significant at $99 \%$ level $(P=0.0012) ;{ }^{*}$ difference is significant at $90 \%$ level $(P=0.057)$. The gender difference is not significant $(P=0.279)$.

The second result of interest is that the main difference between the disciplines lies in the extent to which research collaborations are diverse with respect to age and academic rank. Research teams in ancient history tend to seek homogeneity in academic rank, and the maximum age difference between any two authors in a collaboration is much smaller than it is in demographic research. This becomes more evident when we contrast the distribution of rank differences (see Figure 4).

\section{Fig. 4 Heterogeneity in research collaborations: academic ranks of co-authors}

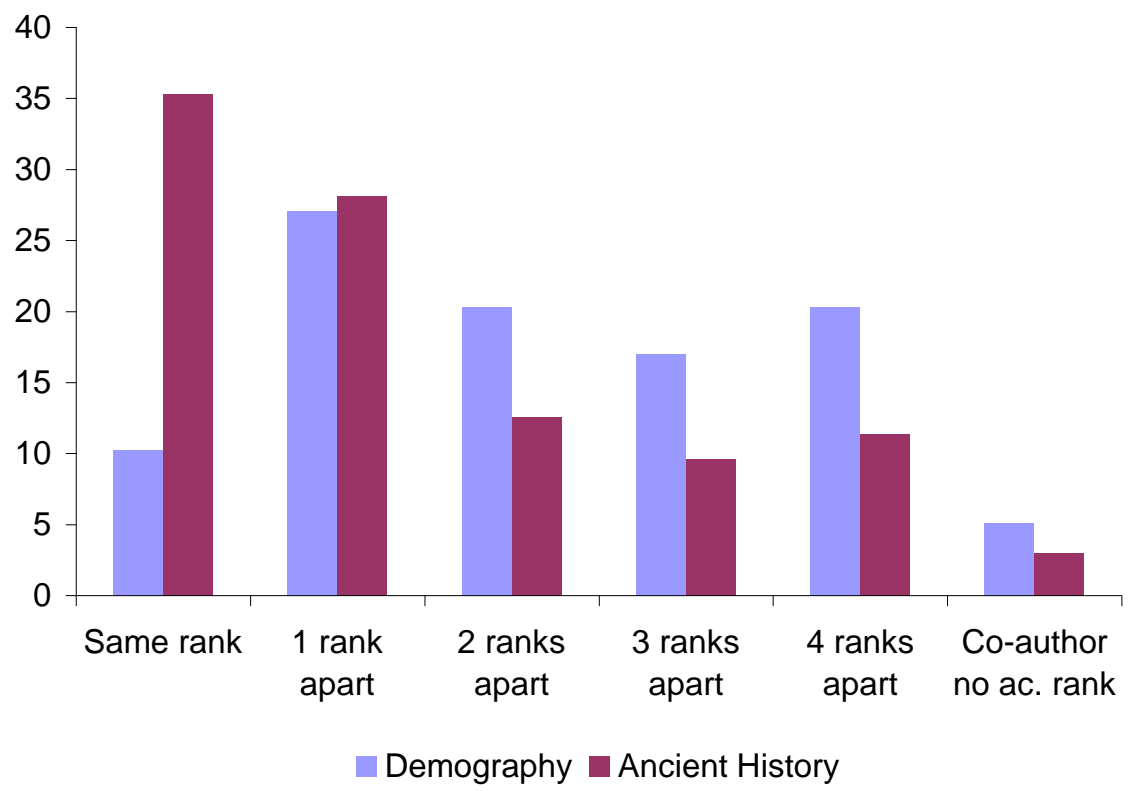


Note: Values specify maximum rank distance between any two co-authors for publications with 2-4 co-authors. $\mathrm{N}$ of joint publications in ancient history $=174 ; \mathrm{N}$ of joint publications in Demography $2012=62$.

This histogram makes the difference very evident: demographers almost seem to avoid collaborating only with colleagues in the same rank, and try to span the range of ages and academic positions within single collaborations. Ancient historians rather tend towards the opposite. They may either actively prefer a same status collaborator, or lack sufficient access to platforms facilitating intensive and long-lasting interactions between colleagues of different ages and ranks of the kind necessary for establishing such collaborations.

The intergenerational orientation of joint research in demography does not merely reflect intensive collaboration between professors and their $\mathrm{PhD}$ students: when collaborations with $\mathrm{PhD}$ students, which might invoke debate over what distinguishes supervision from collaboration, are excluded, intergenerational endeavours are still much more prominent in demography (see Figure 5). This result is in line with the relatively marginal role collaborations with $\mathrm{PhD}$ students played in the personal incentives professors listed for joining forces in research: in only $14 \%$ of cases did the professors interviewed for the study by Melin decide to establish a research collaboration because they were in a student-supervisor relationship with a coauthor. ${ }^{14}$

Figure 5. Beyond supervision: Intergenerational collaborations between academics beyond the PhD-student level

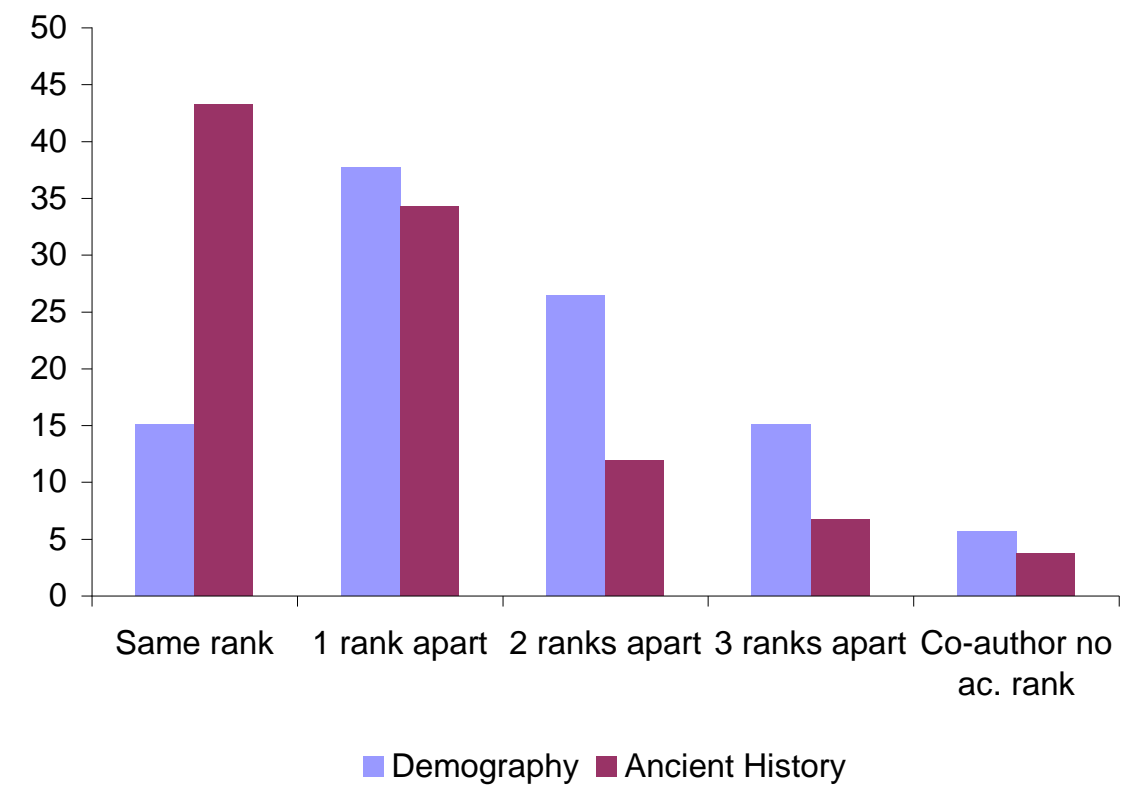

Note: This graph displays the maximum distances in rank between any to co-authors excluding PhD student collaborators from the sample. $\mathrm{N}$ of ancient history publications: 134. $\mathrm{N}$ of publications in Demography: 53.

In the sample of publications from Demography 2012, one may find, for example, an article jointly written by a postdoc in Europe and a full professor in the US - not one of the former advisors of the postdoc during his $\mathrm{PhD}$ trajectory - with a difference of 42 years separating the date of $\mathrm{PhD}$ attainment between the two men. Another example is that of a full professor publishing a joint article with two assistant professors in a different country, one of whom received a PhD twenty-three years later than the full professor did. Neither of the assistant professors got their $\mathrm{PhD}$ degree at any of the universities the senior full professor had been associated with or taught at during the twenty-five years of his post-PhD career. Evidently they met and established connections through wider research networks and encounters in the academic community. As both the quantitative data and the examples of individual cases illustrate, exchange of information and the transfer of knowledge across the generations is more intense in the field of demography - regardless of whether we include $\mathrm{PhD}$ students in the equation, or look only at diversity in age and academic rank among collaborators beyond the PhD-level. In ancient history, this type of intensive collaboration and information exchange is marginalized. When one further takes into account the minor role played by research

\footnotetext{
${ }^{14}$ Melin (2000); cited also in Lee and Bozeman (2005).
} 
collaborations overall, the relative absence of intergenerational interactions at high intensity level becomes all the more evident.

Are there any consequences to this lack of intergenerational exchange? Is anything lost to our research? The question arises whether or not this type of homogeneity in existing collaborations is a source for concern in the sense that it might provide an obstacle against a take-off of contagion effects in collaboration, or in some ways reduces the potential for innovation in ancient history as a research discipline. Empirical research focusing on the role of intergenerational collaboration in academia from this specific perspective is limited. Whereas the roles of gender and ethnicity and the effects of homogeneity versus heterogeneity on these fronts are well articulated in research literature, those of age and generation remain undertheorized. ${ }^{15}$ The answers to these questions are hence open for discussion. But there are a few studies that provide insight.

Among them is an analysis based on a survey among research-oriented liberal arts colleges in the US on intergenerational research collaborations between junior and more senior faculty. Respondents to the survey repeatedly pointed out that there was no competition within this type of collaboration, and that this made the collaboration more agreeable, more open, and more desirable than same-rank collaborations. ${ }^{16}$ As we have seen, indeed the perception of strong competition negatively affects propensity to collaborate, and competition for recognition, rewards, and career advancement arguably concentrates within rather than between cohorts. This suggests that structuring collaboration along intergenerational lines rather than seeking same rank collaborations takes away some of the disincentives for researchers to collaborate.

Secondly, research brings to the fore that establishing a culture of collaboration requires training academics to work together. ${ }^{17}$ The contrast between the strong presence of collaborations between senior and junior faculty and between senior faculty and graduate students in the field of demography and the relative absence of this type of collaboration in leading classics and ancient history departments may therefore go some way in helping to understand why collaborative research is the norm in one setting but not in the other. Engagement in joint research projects is not part of the socialization process of more than a few ancient historians.

Alongside issues regarding rewards and recognition, a lack of awareness of the intrinsic advantages of this type of intergenerational research collaborations may also underlie the marginal role played by this type of collaboration. Interestingly, in the study I just referred to, senior faculty in particular emphasized how producing joint work with untenured or junior faculty brought them new ideas, excitement and a sense of renewal into their professional experience. This may point to some role for intergenerational collaborations in the generation of new ideas and innovation. Untenured junior faculty emphasized the benefits of knowledge transfer through this type of collaboration. They reported that they benefited from the research experience of their senior collaborators, that they became more efficient in their work, and that they gained access to broader networks of scholars that aided their ability to publish and win grants. Both groups reported that their teaching benefited from their intergenerational research collaborations and that they experienced less isolation. ${ }^{18}$

\section{Fostering research collaboration in practice}

Theoretical and experimental studies on research collaboration, in sum, point out several benefits to and incentives for research collaboration. The evidence suggests that both the quality of research outputs in ancient history and the field of ancient history as a community of scholars may benefit from shifting some of its attention and appreciation towards collaborative research, especially where it concerns joint projects that involve researchers across generations. For some of the research directions that leading scholars at this venue identify as 'the future of ancient history', such collaborations are indeed indispensable.

But a culture of individualism that regards collaborative work as something only the sciences could benefit from, and in which the reward system undervalues multi-authored publications provide strong obstacles for individual researchers to join forces and produce something that is more than the sum of the individuals as a result. An investigation of current research collaborations among faculty in ten leading Classics and Ancient History departments, and a comparison with governing practices in the strongly

\footnotetext{
${ }^{15}$ Grenier (2007).

${ }^{16}$ McDaniels (2008).

${ }^{17}$ Bohen and Stiles (1998).

${ }^{18}$ McDaniels (2008).
} 
interdisciplinary field of demography has identified clear challenges for the future of disciplinary and interdisciplinary collaborations. If, to get back to Robyn Veal's challenging remarks, ancient historians are to take the initiative for and encourage the flowering of research collaborations and crossing boundaries research, what can we do in practice?

Spying on demographers, and checking these observations against available literature on fostering research collaboration delivers several suggestions. In the final section of this paper, I focus on smaller rather than larger ideas - ideas that might be carried out by individuals or smaller groups - although I will also touch upon some of the core challenges that would require more fundamental changes at higher levels of organization. It is vital for the success of the future of ancient history, in my view, that we not only define our research goals and directions, but pay equal attention to the question of how to pave the way towards these goals. The following suggestions form a first start for discussion.

\subsection{Create interdisciplinary platforms that are longer-lasting and more intensive than conferences}

Conferences serve a function in bringing together scholars from different disciplines, but the types of interactions involved are relatively short and relatively passive, focused on presenting research findings to a different community. Collaborative research and co-authorships are relationships of trust. Most people need more time and more active interactions to build this up than conference settings allow for. One type of platform demographers use to foster interdisciplinary collaborations is that of a workshop. These workshops are very far from the type of workshop that is more or less a conference that presents work in progress. Rather, thematically or methodologically driven meetings that take a week or sometimes significantly longer and are halfway between a course and a 'projectweeks'. Essentially these weeks acquaint small groups of scholars with colleagues and methods of other disciplines by combining lectures and group-projects. These are explicitly not venues only for graduate students, but ones that unite people regardless of rank, and include from student to research institute director. This is a structure that encourages groups of two or three people formed for the week or so to continue working on their project to turn it into a publication after the end of physical closeness.

\subsection{Databases \& data sharing}

Among ancient historians, it is a complaint not seldom heard that the datasets that underlie articles published by classical scholars are not made available publicly, so that it is impossible to evaluate the arguments of the work, there is no tendency towards congruence in methodology, and it is hardly possible to incorporate published data into larger comparative research. What can we do beyond complain? One of the lessons we, as ancient historians, may certainly draw from 'spying on demographers' is that reluctance and unwillingness to share data are not unique to the field of ancient history or the humanities. Data sharing is not always selfevident in demographic research either. Demographers need to convince managers of zoos, directors of archives, government officials wary of privacy and data misuse and historians who often spent years collecting their evidence to provide them with often sensitive data on health, migration and survival. What factors contribute to their success in getting colleagues and others to share data? First of all, demographers agree and accept that getting access to data is a process that may take major investments of research time. They succeed by investing time in building trust, by making others believe that they will take part in exciting research projects driven by eminent scientists, by being assuring about credentials and by taking away effort for donators through taking over all or part of the data processing. Sometimes these exchanges are between individual researchers, but often leading institutions 'intermediate' and function as platforms for data sharing. When people can donate data to a partnership that is visible online, connected to a trustworthy institution, this inspires more confidence than when data have to be handed over to an unknown or only vaguely known individual. While governed by such an institution, these databases (or at least the one I have been involved with) are explicitly presented as joint projects, crediting all donators and officially including them as partners involved in the project, thus emphasizing that the interest of the group is not only in the donated data, but in the donator as well. Working groups involving smaller numbers of partners function as bodies trying to attract funding to facilitate research on the basis of donated data and to facilitate collection of further data. Database projects also explicitly seek to avoid reinventing the wheel by inviting specialists to provide advice at early stages.

Another important role in establishing and maintaining a research culture of data sharing is played by journals and their editorial boards. Unlike in ancient history, in the field of demography publishers and 
editing boards of journals may and often do require authors submitting papers to provide the research community access to their raw data. By way of illustration, a quote from Demography, the journal drawn upon for the demographic dataset, and one of the top ranking journals for demographic research:

'Editorial Policy: (...) Manuscripts submitted to Demography will be judged, in part, by whether they have reconciled their results with already-published research on the same topic. Authors of accepted manuscripts will be asked to preserve the data used in their analysis and to make the data available to others at reasonable cost from a date six months after the publication date for the paper and for a period of three years thereafter. Authors wishing to request an exemption from this requirement (e.g., because the analysis is based on a proprietary data set) should notify the editors at the time of manuscript submission or after receiving this notice; otherwise, authors will be assumed to accept the requirement.'

This is still a relatively mild phrasing: most journals academics working on evolutionary demography wish to publish in simply demand them to add their dataset to their paper submission. In other words, if a researcher is unwilling to make his or her data available to others, this researcher is simply out of the game. Needless to say, in a start-up phase journals in ancient history with an interest in articles based on quantitative data such as bodies of inscriptions or archaeological material may run the risk of losing some contributors. But if and when these pioneers include the top ranking journals in the field, utilitarian motives are likely to quickly overrule such reluctance. If the editorial boards of journals like The Journal of Roman Studies and the Journal of Roman Archaeology would decide to include and publish similar demands as part of their editorial policies, and consistently decline to publish work from authors who do not meet that demand, broader access to raw datasets might not be a fata morgana for long anymore.

\subsection{The role of leadership in fostering research collaboration}

Senior researchers play important roles in bringing about research collaborations. As Bohen and Stiles comment in an analysis of factors that promoted success at interdisciplinary collaboration at Harvard University, 'the second ingredient...is leadership, specifically strong senior faculty leadership with the ability to bridge intellectual boundaries, and the skills of an idea integrator, rapporteur and fundraiser'. Similarly, the 2004 US National Academy of Sciences Report recommends that senior scholars mentor students as well as junior colleagues who wish to work on interdisciplinary problems as a strategy to enhance interdisciplinary collaborations. In the case of the demographic research institute I am connected with, it is noticeable that collaborations, also those that do not actively involve the respective senior researcher as an investigator for the project, were often spurred with the help of the oversight, experience, network and/or reputation of this senior researcher. Our directors virtually run dating bureaus, linking people through their search engines, setting up first dates (in their presence), and providing counselling as needed along the research project's route to bridge intellectual boundaries. Without their engagement, there would be many fewer, and more less successful interdisciplinary research collaborations.

\subsection{Creating incentives for collaboration: carrots and sticks}

Bibliometric analysis of joint research in ancient history has made clear that collaborations tend to take place within academic cohorts rather than between them, while research shows that competitiveness is an obstacle that in particular prohibits the spread of collaborations among same-rank peers. As we have seen, cross-rank collaborations are perceived of as more desirable, among others because of the absence of competition between co-authors. Increasing intergenerational exchange could thus provide a tool for fostering research collaboration in ancient history.

At the same time, some studies on research collaboration do not find any relation between the perceived level of competition and willingness to collaborate. Scholars in several scientific fields consider themselves to be working under heavy competitive pressure, but share their data, and produce co-authored work even so. In these settings, the benefits of collaboration are perceived to outweigh its disadvantages in terms of career advancement. ${ }^{19}$ This phenomenon points to the importance of 'research culture' and the ways

\footnotetext{
${ }^{19}$ Birnholz (2007). Note also the classic study by Zuckerman (1977) that demonstrated how the scientific success of future Nobel Prize Winners was spurred by involvement in research collaboration rather than by working solely. Zuckerman studied the scientific trajectory of American Nobel Prize winners, and found that during the period prior to
} 
in which scientific fields attribute recognition and shape preconditions for reward. ${ }^{20}$ Among these, the evaluation of joint research activities during promotion and tenure decisions is of particular relevance. Enhanced recognition of these activities aligns collaboration and career development opportunities, and may therefore, according to the 2004 US National Academy of Sciences report, vitalize collaborative research.

Similarly, the availability of platforms to publish interdisciplinary work is recommended in the literature as a way of creating incentives for interdisciplinary research. One route, so it suggests, could be the creation of special issues of existing journals or the creation of a new journal; another the inclusion of researchers with interdisciplinary expertise in addition to researchers with expertise in the core discipline. ${ }^{21}$ Countering potential negative effects of collaboration to individual researchers and research careers thus forms one way to foster the research collaborations that are paramount to developing many of the research directions ancient historians regard as the future of their discipline.

\section{References}

Barjak, F. and Robinson, S. (2008) 'International collaboration, mobility and team diversity in the life sciences: impact on research performance', Social Geography 3: 23-36.

Birnholtz, J. P. (2007) 'When do researchers collaborate? Toward a model of collaboration propensity', Journal of the American Society for Information Science and Technology 58.14: 2226-2239.

Birnholtz, J. P. and Bietz, M. J. (2003) 'Data at work: Supporting sharing in science and engineering', in Pendergast, M., Schmidt, K., Simone, C. and Tremaine, M. (eds) Proceedings of the International ACM SIGGROUP Conference on Supporting Group Work. New York.

Blumenthal, D., Campbell, E.G., Anderson, M. S., Causino, N. and Louis, K. S. (1997) 'Withholding research results in academic life science', Journal of the American Medical Association 277.15: 1224-1228.

Boardman, P. C. and Corley, E. A. (2008) 'University research centers and the composition of collaborations', Research Policy 37: 900-913.

Bohen and Stiles (1998) 'Experimenting with models of faculty collaboration: factors that promote their success', New Directions for Institutional Research 100: 39-55.

Bozeman, B. and Corley, E. (2004) 'Scientists' collaboration strategies: implications for scientific and technical human capital', Research Policy 33.4: 599-616.

Franchescet \& Costantini (2010) 'The effect of scholar collaboration on impact and quality of academic papers', Journal of Informetrics 4: 540-553.

Gazni, A., Sugimoto, C. R. and Didegah, F. (2012) 'Mapping world scientific collaboration: authors, institutions and countries', Journal of the American Society for Information Science and Technology 63.2: 323-335.

Gibbons, M., Linoges, C., Nowotny, H., Schwartzman, S., Scott, P. and Trow, M. (eds.) (1994) The new production of knowledge: the dynamics of science and research in contemporary societies. Sage.

Grenier, A. M. (2007) 'Crossing age and generational boundaries: exploring intergenerational research encounters’, Journal of Social Issues 63.4: 713-727.

Lee, S. and Bozeman, B. (2005) 'The impact of research collaboration on scientific productivity', Social Studies of Science 35: 673-702.

Logan and Shaw (1991) 'A bibliometric analysis of collaboration in a medical specialty', Scientometrics 20.3: 417-426.

McDaniels, M. (2008) Intergenerational research collaborations at research-oriented liberal arts colleges: an ecological approach to faculty development. $\mathrm{PhD}$ dissertation, Michigan State University.

Melin, G. (2000) 'Pragmatism and self-organization: Research collaboration on the individual level', Research Policy 29.1: 31-40.

National Academy of Sciences (2004) Facilitating interdisciplinary research. Washington DC.

Presser, S. (1980) 'Collaboration and the quality of research', Social Studies of Science 10: 95-101.

their award with a Nobel Prize, future laureates did not publish significantly more single-authored papers than less successful peers (ca. 20\% more). What distinguished them from other promising scientists was rather the amount of jointly authored articles they published: for every three articles other productive scientists published jointly, they produced eight, or 170\% more. See esp. Zuckerman (1977) 176.

${ }^{20}$ Van Rijnsoever and Hessels (2011).

${ }^{21}$ National Academies of Sciences 2004. 
Rhoten, D. and Pfirman, S. (2007) 'Women in interdisciplinary science: exploring preferences and consequences', Research Policy 36: 56-75.

Van Rijnsoever, F. J. and Hessels, L. K. (2011) 'Factors associated with disciplinary and interdisciplinary research collaboration', Research Policy 40: 463-472.

Walsh, J. P. and Hong, W. (2003) 'Secrecy is increasing in step with competition', Nature 422.6934: 801802.

Wray, K. B. (2002) 'The epistemic significance of collaborative research', Philosophy of Science 69.1: 150-168.

Zuckerman, H. (1977) Scientific elite: Nobel Laureates in the United States. New York. 